\title{
DETERMINAÇÃO DE CURVAS DE EQUILÍBRIO SÓLIDO- LÍQUIDO DE SOLVENTES EUTÉTICOS PROFUNDOS (DES) EMPREGANDO A CALORIMETRIA EXPLORATÓRIA DIFERENCIAL (DSC)
}

\author{
H. PLETSCH ${ }^{1}$, M.C.G.C. DIAS ${ }^{2}$ e M.R. MAFRA ${ }^{3}$ \\ ${ }^{1}$ Universidade Federal do Paraná, Curso de Graduação em Engenharia Química \\ ${ }^{2}$ Universidade Federal do Paraná, Programa de Pós-Graduação em Eng. de Alimentos \\ ${ }^{3}$ Universidade Federal do Paraná, Departamento de Engenharia Química
}

E-mail para contato: pletschhelena@gmail.com

\begin{abstract}
RESUMO - Os solventes eutéticos profundos (DES) constituem potenciais alternativas ao uso de compostos orgânicos tóxicos e voláteis nas indústrias farmacêutica, alimentícia, química e petroquímica. Entretanto, devido ao estado inicial em que se encontram as pesquisas relacionadas aos DES, faz-se necessário a investigação aprofundada das propriedades físico-químicas e das possíveis aplicações de tais solventes. Assim, este trabalho objetivou a síntese e a determinação de propriedades térmicas de DES formados por cloreto de colina e etilenoglicol. Os sistemas de DES utilizados no estudo foram facilmente sintetizados e as suas transições avaliadas por meio da calorimetria exploratória diferencial (DSC). A aplicação desta técnica possibilitou a construção do diagrama de equilíbrio sólido-líquido do sistema de cloreto de colina e etilenoglicol.
\end{abstract}

Palavras-chave: solventes eutéticos profundos, cloreto de colina, etilenoglicol, DSC, equilíbrio sólido-líquido.

\section{INTRODUÇÃO}

A crescente preocupação mundial com problemas ambientais provocou grandes impactos na Engenharia Química e motivou o desenvolvimento de substâncias e processos industriais menos nocivos ao meio ambiente e ao ser humano. Desta forma, uma nova área de pesquisa, conhecida como "química verde", assumiu um papel de grande destaque. Dentre os diversos aspectos explorados por essa nova vertente científica, encontra-se a substituição de solventes orgânicos tóxicos e voláteis, empregados em grade extensão em diversos processos da indústria, por compostos biodegradáveis (Khandelwal et al., 2016).

Um dos avanços tecnológicos de maior destaque da química verde compreende os "líquidos-iônicos" (LIs). Segundo Dai (2013), devido à manifestação de propriedades como 
baixa pressão de vapor, excelente estabilidade térmica e viscosidade ajustável, os LIs constituem importantes alternativas aos solventes orgânicos voláteis. Além disso, os LIs podem ser sintetizados em função da polaridade e seletividade desejadas em uma determinada aplicação industrial e, desta forma, possuem grande capacidade de serem aplicados tanto para sistemas orgânicos quanto inorgânicos (Khashayar, 2014). No entanto, ainda de acordo com Dai (2013), os LIs apresentam alto custo de produção e sua síntese demanda, na maioria dos casos, o uso de precursores tóxicos.

Alternativamente, pesquisadores (Abbot et al., 2003; Dai, 2013) estudaram uma nova classe de fluidos, análogos aos líquidos iônicos, e conhecidos como solventes eutéticos profundos ( DES, do inglês "Deep Eutectic Solvents"). Os DES são substâncias formadas pela mistura eutética de ácidos e bases de Lewis. Geralmente, os DES são obtidos através da complexação de um sal quaternário de amônio com um doador de ligação de hidrogênio (HBD, do inglês "Hydrogen Bond Donor"). Uma das principais características dos DES são as suas baixas temperaturas de fusão, com valores consideravelmente inferiores aos pontos de fusão dos seus constituintes puros. Segundo Abbot et al. (2014), esta redução na temperatura de transição sólido-líquido característica dos DES é resultado da formação de ligações de hidrogênio entre os compostos presentes no sistema.

Os DES apresentam vantagens em relação aos LIs pois, além de possuírem propriedades físico-químicas semelhantes, a síntese de tais solventes eutéticos engloba rotas relativamente simples e baratas, as quais não envolvem o uso de precursores tóxicos. Adicionalmente, estudos reportam importantes aplicações de DES na indústria alimentícia, farmacêutica, petroquímica e química (Abbot et al., 2014; Dai, 2013).

Em vista do potencial uso dos solventes eutéticos profundos como alternativas "verdes" aos solventes tradicionalmente empregados na indústria, o presente trabalho objetiva aprofundar o conhecimento das propriedades termodinâmicas de alguns dos sistemas formadores de DES. Para tanto, serão estudados os comportamentos térmicos e as curvas de equilíbrio sólido-líquido de misturas contendo cloreto de colina e etilenoglicol (HDB) através da técnica de calorimetria exploratória diferencial (DSC).

\section{SEÇÃO EXPERIMENTAL}

Cloreto de colina $(\mathrm{ChCl})$ (pureza em fração mássica $>99,0 \%$ ), produido pela Merck, e Etilenoglicol P.A. (EG) (pureza em fração mássica >99,5 \%), fabricado pela Biotec, foram previamente secos e misturados seguindo diferentes proporções molares. Os reagentes foram pesados individualmente em uma balança analítica AL 204 Mettler Toledo, respeitando as proporções molares de etilenoglicol de $0 \%, 30 \%, 50 \%, 70 \%, 90 \%$ e $100 \%$. Em seguida, os reagentes foram adicionados a um béquer e a mistura sólida foi homogeneizada com o auxílio de um bastão de vidro.

As misturas sólidas contendo as diferentes proporções de precursores foram levadas a um banho maria Dubnoff previamente estabilizado em $60^{\circ} \mathrm{C}$ e com rotação orbital de 220 rpm. As amostras permaneceram no banho por aproximadamente $30 \mathrm{~min}$, tempo suficiente para que se pudesse observar a formação de líquidos homogêneos. Os DES sintetizados foram retirados do banho e armazenados em um dessecador a fim de controlar a umidade e promover resfriamento natural. 
A caracterização térmica dos DES envolveu o uso de calorimetria exploratória diferencial (DSC). A determinação do ponto eutético, da transição vítrea, da transição sólidosólido (polimorfismo) e da fusão das amostras foi realizada empregando o equipamento DSC 8500 PerkinElmer. Cerca de $5 \mathrm{mg}$ de DES foram pesados em panelinhas padrão de aço inoxidável. Foi utilizado nitrogênio (pureza $>99,999 \%$ da White Martins) como gás de purga a uma vazão de $20 \mathrm{~mL} \mathrm{~min}^{-1}$. As amostras, inicialmente à $20^{\circ} \mathrm{C}$, foram resfriadas até $-100{ }^{\circ} \mathrm{C}$. Em seguida, as mesmas foram aquecidas $\left(5^{\circ} \mathrm{C} / \mathrm{min}\right)$ até $30^{\circ} \mathrm{C}$, temperatura na qual as misturas foram mantidas por um breve intervalo de tempo $(10 \mathrm{~s})$. Em seguida a amostra era resfriada até $-100^{\circ} \mathrm{C} \mathrm{a}$ uma taxa de $5{ }^{\circ} \mathrm{C} \mathrm{min}^{-1}$. Foram realizados três ciclos de aquecimento e resfriamento de forma a evitar problemas de "memória térmica" do material e também a fim de favorecer a cristalização da amostra na forma mais estável, caso o sistema apresentasse polimorfismo.

\section{RESULTADOS E DISCUSSÕES}

A metodologia empregada para a análise DSC possibilitou a observação de pontos de polimorfismo, cristalização e fusão das amostras preparadas. Adicionalmente, os eventos térmicos observados no DSC apresentaram reprodutibilidade em, ao menos, dois dentre os três ciclos de aquecimento e resfriamento conduzidos. A Figura 1 apresenta o resultado obtido para os três ciclos de aquecimento e resfriamento do DES contendo $90 \%$ de etilenoglicol. As demais amostras, com as composições descritas na seção experimental, apresentaram curvas semelhantes.

Figura 1 - Curvas de DSC (3 cilcos) para a amostra contendo $10 \%(\mathrm{~mol} / \mathrm{mol})$ de $\mathrm{ChCl}$ e $90 \%(\mathrm{~mol} / \mathrm{mol})$ de etilenoglicol. A seta orientada para a direita indica o aquecimento da amostra, enquanto que a orientada para a esquerda indica a etapa de resfriamento.

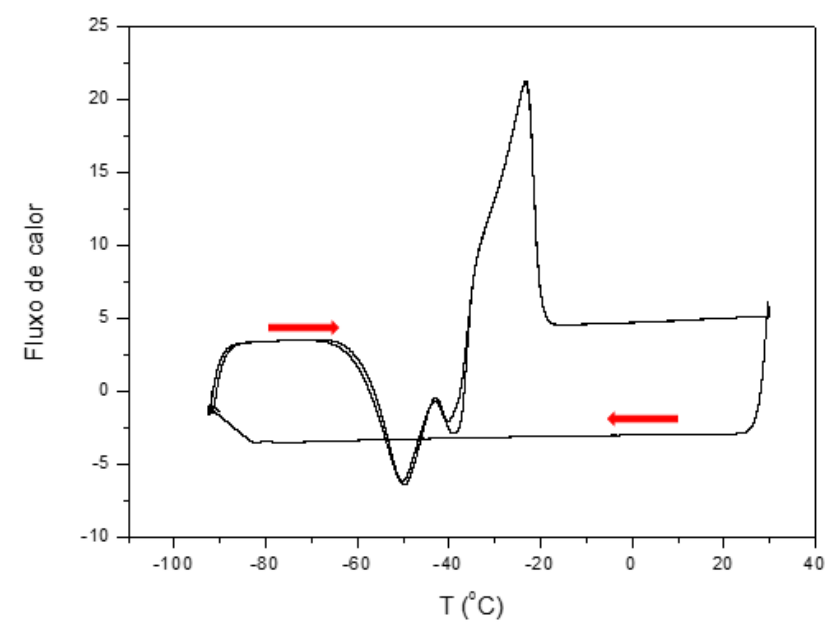

Na Figura 2 é possível visualizar, durante os ciclos de aquecimento, a ocorrência de eventos exotérmicos. Estes eventos, que ocorrem em sequência, provavelmente estão associados a transições sólido-sólido (polimorfismo) e à estabilização do DES. A uma temperatura imediatamente superior àquela em que uma possível transição entre fases sólidas ocorre, observa-se a existência de um pico endotérmico. Evidências indicam que este pico representa a fusão do DES. Picos semelhantes foram obtidos para todas as amostras analisadas, com variações na temperatura de ocorrência e na intensidade de fluxo de calor. 
Figura 2 - Resultado de segundo ciclo de aquecimento (a) do DSC obtido para amostra contendo $10 \%$ ( $\mathrm{mol} / \mathrm{mol})$ de $\mathrm{ChCl}$ e $90 \%$ ( $\mathrm{mol} / \mathrm{mol})$ de etilenoglicol. Picos indicando polimorfismo (b), cristalização (d) e fusão (c) do DES.

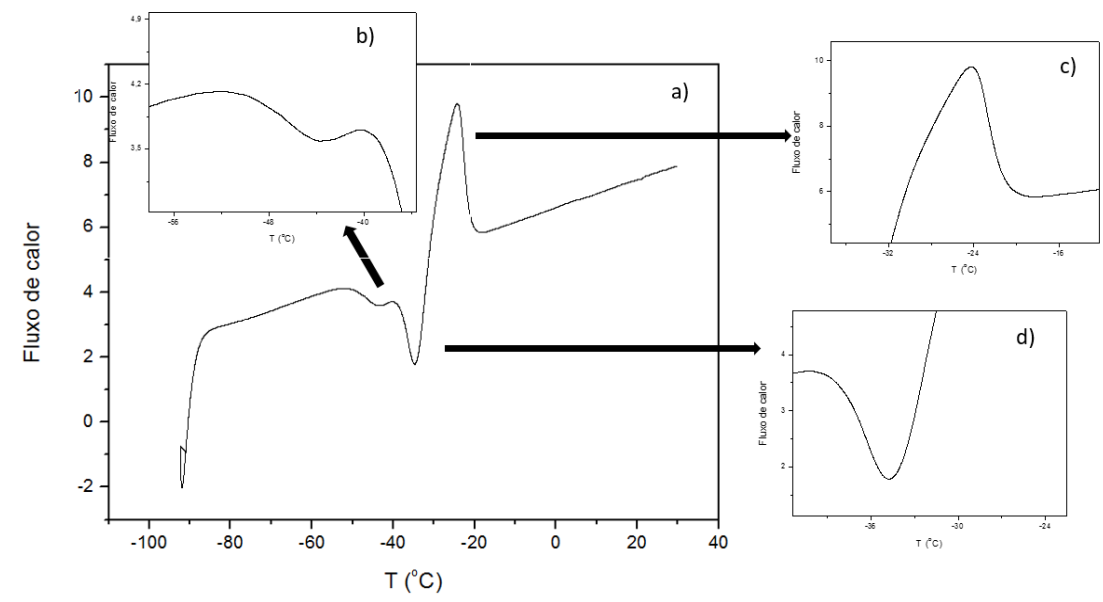

Em posse dos resultados do DSC e das temperaturas de fusão das diferentes amostras testadas, foi possível obter o diagrama de equilíbrio sólido-líquido para o sistema formado por cloreto de colina e etilenoglicol. O ponto correspondente ao eutético da mistura, associado à $\mathrm{X}_{\mathrm{EG}}=0,67$ e temperatura de fusão de $-40{ }^{\circ} \mathrm{C}$, é um valor teórico encontrado em diversos trabalhos, dentre eles Dai (2013). O diagrama encontra-se na Figura 3.

Figura 3 - Curva de equilíbrio sólido-líquido obtido para os DESs formado por cloreto de colina e etilenoglicol: " este trabalho, * Dai (2013).

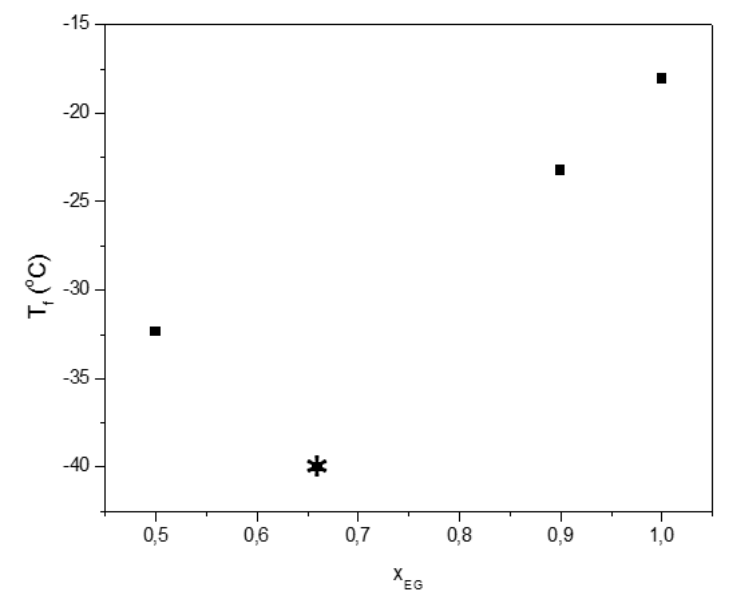

A análise do diagrama indica a existência do ponto eutético para o sistema formado por cloreto de colina e etilenoglicol. Experimentos futuros devem ser realizados a fim de confirmar a presença do ponto eutético e do polimorfismo do sistema.

\section{CONCLUSÕES}


Neste presente trabalho foi possível confirmar que misturas de cloreto de colina e etilenoglicol ( $\mathrm{ChCl}+\mathrm{EG})$ podem formar solventes eutéticos profundos. Ainda, mostrou-se que o sistema de DES envolvendo tais precursores pode ser facilmente sintetizado a partir de uma rota economicamente viável e que não envolve substâncias tóxicas. A caracterização do equilíbrio sólido-líquido da mistura de $\mathrm{ChCl}$ e EG pode ser desempenhada através de uma metodologia de DSC relativamente simples e eficaz. A técnica foi capaz de fornecer dados de pontos de fusão e permitiu, desta forma, a construção do diagrama de equilíbrio sólido-líquido para o DES estudado.

Apesar dos resultado positivos deste trabalho, é fundamental realizar investigações mais aprofundadas sobre o comportamento térmico e sobre as propriedades físicas do sistema de $\mathrm{ChCl}$ e EG. Adicionalmente, pretende-se testar, em estudos futuros, a metodologia de DSC para diversos sistemas de DES, em especial aqueles formados a partir de $\mathrm{ChCl}$ e glicerol.

\section{NOMENCLATURA}

DES - Solventes eutéticos profundos, do inglês "Deep Eutectic Solvents".

DSC - Calorimetria exploratória diferencial.

HDB - doador de ligações de hidrogênio, do inglês "Hydrogen Bond Donnor".

$\mathrm{ChCl}$ - Cloreto de colina.

EG - Etilenoglicol.

$\mathrm{X}_{\mathrm{E}}-$ Fração molar de etilenoglicol na mistura.

\section{REFERÊNCIAS}

ABBOTT, A. P.; CAPPER, G.; DAVIES, D. L.; RASHEED, R. K.; TAMBYRAJAH, V. Novel solvent properties of choline chloride/urea mixtures. Chem. Commun., p. 70-71, 2003

ABBOTT, A. P.; CULLIS, P. M.; GIBSON, M. J.; HARRIS, R.C.; RAVEN, E.. Extraction of glycerol from biodiesel into a eutectic based ionic liquid. Green Chemistry, v. 9, p. 868872, 2007.

ABBOTT, A.P.; SMITH, E.L.; RYDER, K.S. Deep Eutectic Solvents (DES) and Their Applications. Chemical Reviews, v. 114 (21), p. 11060-11082, 2014.

DAI, Y.. Natural Deep Eutectic Solvents and their application in natural product. Tese (Ph.D), 186 f. - Universidade Leiden (Holanda), 2013.

KHANDELWAL, S.; KUMAR, MAHENDRA.; TAILOR, Y.K. Deep eutectic solvents (DESs) as eco-friendly and sustainable solvent/ catalyst systems in organic transformations. Journal of Molecular Liquids, v. 215, p. 345-386, 2016. 
KHASHAYAR, G. A Review of Ionic Liquids, Their Limits and Applications. Green and Sustainable Chemistry, v. 44, p. 44-53, 2014 